\title{
Narrative Inquiry on the Formation of Practical Knowledge of College English Teachers' Teaching Reform
}

\author{
Linzhi Shao ${ }^{1, \text { a }}$ \\ ${ }^{1}$ The Engineering \& Technical Institue of Chengu University of Technology, Leshan, Sichuan, \\ 614000
}

Keywords: College English Teaching Reform, Teachers' Practical Knowledge and Narrative Inquiry

\begin{abstract}
In the teaching reform, teachers as a direct practice, the success or failure of teaching reform plays a direct role. This year, with the advance of the new curriculum reform, the practicality of teaching reform has been pushed to the cusp. The teacher's practical knowledge is closely related to the teacher's own experience, which directly affects and dominates the teacher's behavior and affects the teaching effect. This article uses the fashionable narrative research method to study the actual teaching experience of the college English teachers in the teaching reform, and summarizes the formation and the change of the practical knowledge of the teaching reform, so as to discuss the construction of the practical knowledge in the teacher's teaching reform.
\end{abstract}

\section{Introduction}

In the new curriculum reform, the various subjects teachers have to take measures to change the traditional teaching methods. In the college English classroom teaching reform, not only help students improve their comprehensive ability, as well as teachers professional development. How to promote and from which aspects to start the teaching reform, teachers are holding their views, but unfortunately, the teacher himself pays little attention on the reform of the practice and recognition. This paper argues that teaching reform is actually the reform of the teaching practice process of teachers' teaching methods and teaching modes, and it is not the rules and regulations, but the ones that are recognized in the minds of teachers can play a role in practice "Practical knowledge". In view of this, this paper uses the method of narrative inquiry to describe and reflect the teaching experience of teachers' teaching reform in college English teaching reform, so as to show the practical knowledge displayed by teachers in practical teaching and enrich the understanding of English teaching reform in education department.

\section{The Definition of Practical Knowledge and Narrative Inquiry}

The practical knowledge refers to that in the usual teaching process, through their own practice, summary, thinking, experiment, etc., teachers integrated their own personality and life experience and so on, through long-term, they summed up the rich personality of the educational practice insights and creativity and other related knowledge. Some scholars believe that the so-called practical knowledge refers to the teacher's knowledge that is closely jointed to the classroom situation, highly systematic, processing to automation, and can be employed freely in teaching practice.

Narrative research in education refers to the meaningful, narrative research in teaching is a kind of scientific research form commonly used by teachers, mainly in the way of narrative education research, by telling the story of the way to college English reform In the stories and problems encountered in the description, so as to explore and show these hidden in the daily study, life, behind the behavior of educational significance and ideas. It is straightforward to say that narrative research is to study the practice of meaningful education and teaching, and through the description of the event analysis, in order to reveal hidden in these time and behavior behind the educational ideas and concepts, in order to explore the education and teaching law. 


\section{The Narrative Inquiry of Practical Knowledge Formation of College English Teachers}

The production of practical knowledge of teachers is not simply through the teacher education from top to bottom passive production, It is of great significance to carry out the research on the formation of practical knowledge of college English teachers.

All along, the impact of traditional examination-oriented education, the effectiveness of student learning and teaching evaluation of the basic remain in the learning scores. The use of educational narrative research methods can be very good to help teachers get rid of the traditional education model of imprisonment, so that teachers can boldly open their hands to express their life, education practice in the harvest, vivid, more effective educational experience And knowledge cases.

The traditional English education is mainly books, emphasizing the vocabulary, etc., in the teaching methods are invariably take spoon-type, hard-irrigation teaching methods, ignoring the different teachers of different personality and emotional play and display. After the curriculum reform, it is mainly to construct the theory of stop-loss, action research and other methods to explore the study. The individuality of the teacher's personal temporal knowledge determines that it is difficult to formalize and obtain it directly through the teaching of others. It can only be the teacher's own construction, creation, practice and reflection.

\section{The Formation of Practical Knowledge in College English Teaching Reform}

When the new curriculum began to practice, most teachers are very at a loss, a large number of new vocabulary associated with the curriculum, the new concept was passively communicated to the teachers, but most (almost all) teachers do not know should How to use and implement these new words, only with imagination to explore. Take a teacher in a university in Sichuan as an example: In the beginning of 2003 when the implementation of curriculum reform, teacher: "self-learning" "information education" "formative evaluation" and other core concepts puzzled, do not know how to the implementation of these new ideas and new methods, this time A teacher with the feeling that the so-called self-learning is to allow students to practice oral and listening, so A teacher has taken a quarter of the classroom time to allow students to practice oral and listening, And asked to ask the way, so that students can speak as much as possible English. In addition, A teacher to the traditional plate-book teaching replaced the form of PPT. But in fact, in the teaching process, A teacher and students between the "teacher teaching, student learning" way, is still what the teacher to teach, what students learn, the teacher arranged what students complete what interactive relationship, teachers Is still the center of the classroom. This practice for a semester, this time A teacher found a lot of problems: First of all, open to say that a few students, other students even in the form of skipping to escape the English class, skipping rate has increased.

For the first point of the problem, A teacher access to the relevant information, to reflect on their own teaching methods, this time he found himself a lot of problems. By consulting the relevant research materials, he really understand the "self-learning", "information education" "formative evaluation" and other core values of the true meaning, this time for his teaching methods for a series of reforms. Such as "information education" aspects of the reform: A teachers will be heard and read and write and self-learning to contact students with pre-class with the help of the network and other learning software involved in the basic content of the preview, after the class through the multimedia so that students Can follow the practice of spoken language and so on. A teacher's change so that we can obtain practical knowledge: self-learning is to take the network learning software for preview and review, so that the computer is the main learning tool to achieve the "information construction", so in the classroom time but by the practice with more practice to face and explain, but this time although the teacher A knowledge of the theory and other knowledge has a preliminary understanding, but still can not be out of the teacher-based way, is still all the knowledge of English content in class Time to pour into the students.

Two years after the implementation of the above method, A teacher found that some students have a positive change, but there are still such problems, such as: bring positive changes are 
excellent students, and students studying and learning conditions there is no change, is still not enough consciousness, oral and other reference is too much, the contents of the network learning and teaching materials to repeat, there is nothing new, but let the students into the cycle that the lecture can not speak (Student said a lot which others can not understand), the exam can not pass. This shows that the new curriculum under the new teaching model does not solve the fundamental students are not interested in, do not want to learn, do not want to learn the problem. At this time A teacher into confusion, he did not know whether it should continue, and the requirements of online learning so that a lot of self-control poor students obsessed with the network also made him feel very troublesome, he was very wavering.

Each student is a separate individual, each of them has its own characteristics, in the teaching process, need to take a different learning method, if only to take a single learning method, is unable to meet the different needs of students The A teacher actively learn from education, the reform of their own teaching reform, in the classroom, he heard the training of English as the main content, but not blindly pursue the content, more is to ask the students to listen, say, read, writing, translation and other comprehensive development, in the teaching method is more flexible, comprehensive use, such as the establishment of qq group, so at any time to answer student questions, but also in the classroom to take a variety of teaching methods to practice, to find suitable every student's teaching method.

We have a teacher, for example, the relevant practical knowledge and teachers of the actual teaching behavior of the process of transformation described, it can be seen, A teacher has been completely out of the traditional examination-oriented education and mechanical imitation of the stage, the teaching model and teaching methods Also master a lot, which can be a good way to improve the level of English classroom teaching.

\section{The Impact of Teachers to Create an Important Factor in the Formation of Practical Knowledge}

In general, the formation of practical knowledge is closely related to the teachers themselves, on the one hand and their own character, the environment and so on, the teacher's practical knowledge is the teacher in the process of daily education accumulated, the people of the educational environment (Including the teacher's own experience, experience, teaching classroom environment, social situation, etc.), but also by the external changes (the teacher's own, the people around, leadership, peers, students, etc.) and "things" And change. As in the case, A teacher's change from the initial step-by-step mechanical imitation, later considered the different needs of different students, has been affected by various aspects.

The new curriculum reform is a lot of teachers in the traditional teaching process is not involved, training can make up for their needs in the face of reform, due to their own causes of knowledge, skills and attitudes on the lack of, so that better conduct Purpose, organized teaching activities. In addition, through the training of guidance, strengthen the implementation of advanced theory, to form the correct and effective practical teaching. On the other hand, through training and learning, teachers have a better platform for communication and communication, so that they can better make the existing knowledge more solid, and through communication, learning to absorb the experience of others, thus forming a new practical knowledge.

In general, the teacher's own experience derived from, with a strong individuality. For some new teachers who have just come into contact with teaching reform, their practice knowledge is mainly based on learning and communication, mainly to learn from the experience of predecessors to solve the actual teaching problems, so that the teacher's own ability to improve the effect is not good, Lack of reflection. Novice teachers in the teaching experience and knowledge are derived from books and other people, their actual teaching will encounter what problems, how to deal with the flexible is not particularly clear, only step by step and follow the lesson plan without any doubt.

The practice of teachers' practice is the basis of practical knowledge generation, and it is promoted and perfected by teachers' practical knowledge through the treatment of students' practical problems. Each student is a different individual, to deal with these problems in the students and you 
need to understand each student's personality, individualized, according to their way to communicate, to implement, for students to create a relaxed and active learning atmosphere.

In short, English practice knowledge itself is a very complex implicit theory, is based on the teacher's personal practice, personality, experience and so on from the knowledge system. The only way of this complex knowledge system can only rely on teaching practice, through the study $\rightarrow$ practice $\rightarrow$ reflection $\rightarrow$ re-learning the way to the classroom teaching the entire process of continuous reflection of learning and practice, in order to form a practical knowledge The As A teacher said: "non - stop on their own lessons to reflect on their own way to think about ways to timely find problems and solve the problem, this can be a good way to enhance my teaching effect.

The external factors are mainly institutional factors. Teachers 'qualifications are the prerequisites for teachers' practice and the basic requirements. After the implementation of the curriculum reform, the training of teachers and the actual teaching skills are instructed. These training and guidance exchanges will allow teachers to obtain more Practical knowledge, only to strengthen the training, guidance and communication in order to enable teachers to quickly integrate into, to master some ways and means. It should be noted that, in addition, the need to establish a corresponding incentive assessment system to force teachers to move forward, rather than eating "big pot."

\section{The Role of Reflection and Discussion on the Formation of Practical Knowledge of College English Teachers' Teaching Reform}

The formation of practical knowledge is not early in the morning, with a strong stage, with a teacher, different stages of knowledge and harvest are different, from the accumulation of knowledge to the use of flexible to learn from each other, this is not only to enhance the teaching effect, But also greatly enhance the ability of teachers to their own level. In this process, the detection of continuous teaching reflection is an important way for teachers to develop their own, but also teachers to form, understand and manage their own practical knowledge of the important means. A teacher in the above, for example, is not difficult to find that every time he progress is inseparable from the self-reflection: from the beginning of the imitation, through reflection he felt there is a big problem, and then through the data query and then find the problem, and then after the communication training to be improved again.

For university teachers, the large-scale reform of English teaching is the first time since the Ministry of Education and the leading national curriculum reform activities, but it is necessary, but not just the opportunity, or A huge challenge. Requiring teachers to change the traditional, familiar teaching model, the use of new ways and means to carry out all aspects of challenges and improvements, but also need to keep trying. Only in this way can we formulate a policy that is really suitable for both teachers and students so that we can really implement it, really play a strength for the development of English teaching, enhance the teaching effect and achieve the ultimate goal of curriculum reform.

\section{Conclusion}

In short, this paper takes the method of narrative inquiry, taking A teacher as an example, the main energy of English teachers in practical curriculum reform, and describes and comprehends the formation and change of practical knowledge in this process. From the fact that the results of teachers to take the initiative to explore, take the initiative to reform, is that teachers through practice accumulated practical knowledge, not what rules and regulations, scholars expert advice, but through the teacher in the actual reform summed up Practical knowledge is the final decision of the effectiveness of the reform. Only in the actual teaching process of continuous practice, reflection, change and then practice, reflection ... can we really play the role of reform. Through the study of this article hope to let education back to teaching practice in the province, rather than from the practice of completely separated from the pie, only standing in the position of teacher and analysis, it really found the teacher in the teaching of the problem to improve, which for college English teachers, education management departments have a strong inspiration. 


\section{References}

[1] Wu Peng. College English teacher teaching reform practical knowledge formation of the narrative [J]. Journal of Educational Science, 2011 (1): 59-64

[2] Guo Suihong, Chen Yuanli. A good English teacher practical knowledge of the narrative research [J]. Journal of Qiqihar University, 2013 (3): 157-160

[3] Li Yanhong, Zhang Li. A primary school practice teacher practice knowledge formation narrative research [J]. Journal of Tianshui Normal University, 2016, 36 (2): 74-78

[4] Cui Litao. A new college English teacher practice knowledge narrative research [J]. Northwest Normal University, 2009 